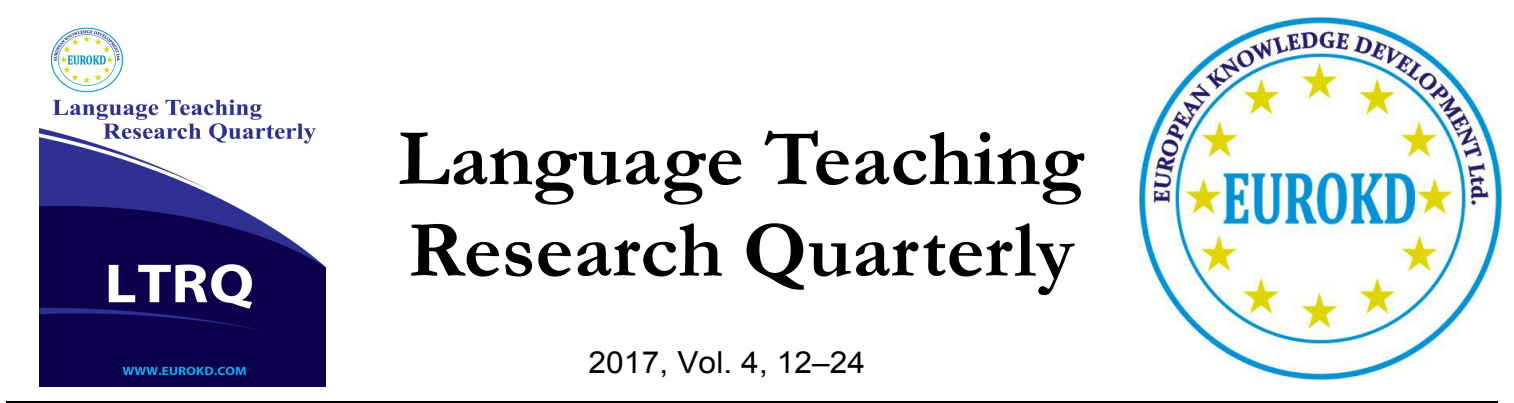

\title{
Emotional Intelligence: Continuing Controversies and Unresolved Issues
}

\author{
Hassan Mohebbi ${ }^{1, *}$, Christine Coombe ${ }^{2}$, Robert Kirkpatrick ${ }^{3}$ \\ ${ }^{1}$ University of Tehran, Iran \\ ${ }^{2}$ Higher Colleges of Technology, Dubai, UAE \\ ${ }^{3}$ Editor-in-chief of Language Testing in Asia
}

Received 23 September 2017 Accepted 11 December 2017

\begin{abstract}
Emotional Intelligence (EI), defined as the "capacity to process emotional information accurately and efficiently" (Mayer \& Salovey, 1995), has recently become one of the most discussed issues in different fields. There has been a great deal of discussion both for and against its potential role in education. In fact, it is argued that there is a significant relationship between EI and success in various aspects of life, including life satisfaction, mental health, self-efficacy, psychological well-being, occupational success, and academic achievement. However, there is a gap with regard to EI and its potential role and application in various fields and contexts. The intention of this paper is to stimulate debate and encourage further research about EI through discussing its definitions, constituents, theoretical framework, measurements, and the criticisms leveled against its alleged unfulfilled promise. Furthermore, we elaborate thoroughly on the directions for future research in this field of study.
\end{abstract}

Keywords: Emotional Intelligence, Emotion, Measurement, MSCEIT, ESC

\section{Introduction}

Emotional Intelligence (EI), simply defined as a "person's capacity to process emotional information effectively" (Mayer \& Salovey, 1995), is a thought-provoking topic in management, organizational leadership, personality and clinical psychology and to a lesser extent in education and is a highly researched idea in the domain of employee behavior (Sharma, Gangopadhyay, Austin, \& Mandal, 2013). 
EI is considered a form of intelligence involving the skill of understanding peoples and especially one's own emotions and to use the emotions strategically to tune one's thought and actions (Morrison, 2007). It is assumed that people with high levels of EI might succeed more readily in life (Costa, Ripoll, Sanchez, \& Carvalho, 2013). In addition, EI plays a key role in various applied domains and, more importantly, in deciding the well-being of individuals and society (Zeidner, Matthews, \& Roberts, 2012). It is also argued that high EI might result in success in personal and professional aspects of life. EI might be employed as a consulting tool that would enhance a person's performance (Lam \& Kirby, 2002). Salovey and Mayer (1990) proposed the construct of EI in 1990. However, the concept of EI dates back to Thorndike's social intelligence in 1920s and Gardner's Multiple Intelligences Theory in the 1980s. Ciarrochi, Chan, and Caputi (2000) remarked that the emergence of EI can be related to the dissatisfaction with the traditional and narrow conceptualization of intelligence. EI marks the intersection of the cognitive and the emotional systems as two key components of personality (Mayer \& Salovey, 1995). EI theory sets a comprehensive framework to investigate the role of emotion in personal, social, and academic affairs (Rivers et al., 2012).

According to Salovey and Mayer (1997), EI "involves the ability to perceive accurately, appraise, and express emotion; the ability to access and generate feelings to facilitate thought; the ability to understand emotions and emotional knowledge; and the ability to regulate emotions to promote emotional and intellectual growth"(p.5). Precisely speaking, EI is a set of abilities that allow the solving of problems encountered in daily life in different contexts (Rivers et al., 2012). In other words, EI refers to the processes used in there cognition, understanding, and measurement of emotions to regulate behavior and solve problems (Brackett \& Salovey, 2006). In fact, EI has been proposed as a coherent framework to explain human beings' outcomes (Salguero, Extremera, Cabello, \& Fernandez-Berrocal, 2015).

Goleman (1998) suggested a unitary construct of EI consisting of "five domains: knowing one's emotions, managing one's emotions, motivating oneself, recognizing emotions in others, and handling relationships" (Waterhouse, 2006). Goleman defined EI as: "abilities such as being able to motivate oneself and persist in the face of frustrations, to control impulse and delay gratification, to regulate one's moods and keep distress from swamping the ability to think, to empathise and to hope" (Goleman, 1995, p. 34).

In recent years, we have witnessed a growing interest in the role and functions of EI in education and in academic success. Mortiboys (2005) claimed that EI deserves to be recognized as an essential element of what all teachers are assumed to provide. Sherlock (2002) argued that a curriculum that takes advantage of EI might enhance the "values of open-mindedness, inclusion, respect, and tolerance" (p.139). However, disappointingly enough, as Sherlock highlights, one of the major challenges to including EI in curricula is the argument that schools are exclusively responsible for developing students' cognitive domain and are not in charge of developing students' affective dimensions. In contrast to this argument, it is highlighted that EI and education are inextricably associated. 
A study conducted by Pishghadam and Sahebjam (2012), found that almost all constructs of EI, namely stress management, adaptability, general mood, and intra- and interpersonal competencies were associated with teacher burnout. Moafian and Ghanizadeh (2009) and Ghanizadeh and Moafian (2010) concluded that we should attach greater importance to the role of EI in language teaching because EI has a significant effect on teaching practices. Therefore, it is imperative to highlight that identifying and regulating the variables that have an effect on the development of teacher EI deserve further and critical consideration. Similarly, Rastegar and Memarpour (2009) reached the same results regarding the relation between EI and teachers' selfefficacy.

Costa and Faria (2015) studied the effect of EI on academic achievement in a Portuguese context. The analysis of data, obtained through a self-report inventory and a performance abilitybased measure, indicated that both measurements could predict students' academic achievement. The findings underscored the overriding importance of fostering students' EI as an effective strategy of promoting academic success.

This paper investigates the status quo of EI research and the debates for and against it. We aim to shed more light on the issues with respect to EI, in particular the conceptual framework of EI, the measurements of EI, and the gaps perceived to be bridged by further research. The next section of the article elaborates concisely on the conceptual and theoretical base of EI.

\section{Theoretical underpinnings of EI}

EI can be associated with general intelligence but it is different from general intelligence in terms of underlying mechanisms, i.e., "emotionality, emotion management, and neurological substrates and manifestations", including "greater verbal fluency in emotional domains and overall information transmission encountering emotional threat" (Mayer \& Salovey, 1993).

Generally, the EI paradigm consists of intrapersonal and interpersonal intelligences. Figure 1 shows the EI paradigm and its constituents adapted from Morrison, 2007. As Figure 1 clearly represents, there is interrelatedness across the four domains.

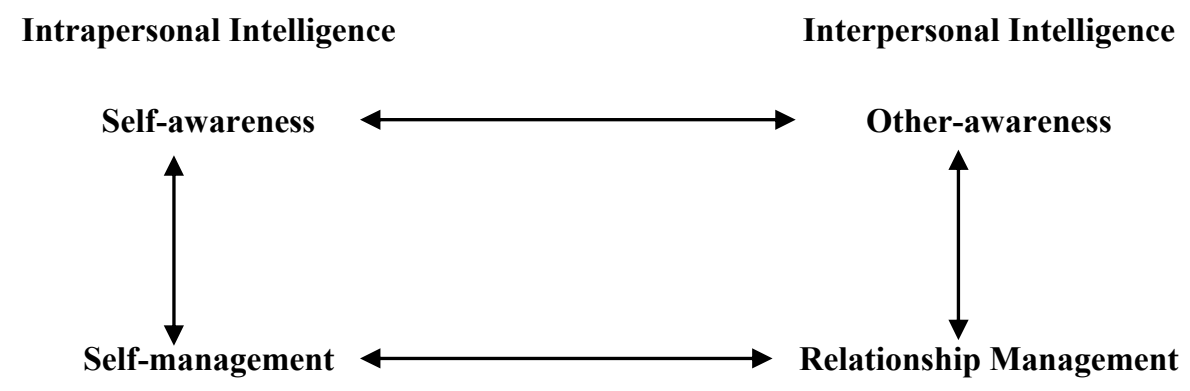

Figure 1. The EI paradigm

Today, theoretical approaches consider EI either as a group of cognitive abilities or skills or as an "array of non-cognitive behavioral dispositions and self-perceptions related to emotional 
functioning" (Brouzos, Misailidi, \& Hadjimattheou, 2014). The theoretical model of EI is a "fourbranch hierarchy"(Anguiano-Carrasco et al., 2015), including emotion perception, facilitation, understanding, and management; the philosophy behind the model is that "skills in the higher branches" are dependent upon those of the lower branches(Anguiano-Carrasco et al., 2015).Furthermore, it is argued that the four abilities of EI have "developmental trajectories and over the course of development", people "mature in their capacity for processing and applying emotional information within each ability area" under different contexts (Rivers et al., 2012). Table 1 summarizes the four constituents of EI.

Table 1

The Constituents of EI (Based on Rivers et al., 2012)

\begin{tabular}{ll}
\hline EI Constituents & Function \\
\hline $\begin{array}{l}\text { Perceiving and expressing } \\
\text { emotion }\end{array}$ & $\begin{array}{l}\text { Identifying and differentiating emotions in one's, peoples', and cultural } \\
\text { expressions' bodily states, feelings, thoughts, and expressions. }\end{array}$ \\
$\begin{array}{l}\text { Using emotion to facilitate } \\
\text { thought }\end{array}$ & $\begin{array}{l}\text { Using emotions to focus attention, to think more rationally, logically, and } \\
\text { creatively, and handling emotions to prioritize thinking and guide attention. }\end{array}$ \\
$\begin{array}{l}\text { Understanding emotion } \\
\text { Knowing the causes of emotions, what emotions signify about goals and well- } \\
\text { being, and how to label emotions accurately? }\end{array}$ \\
\hline
\end{tabular}

In the same line of argument, Goldsworthy (2002, p. 122) presents the EI framework. Table 2 demonstrates the framework.

Table 2

The EI Framework

EI is not static; it can and should be taught.

Emotion and cognition are highly interrelated and need to be treated as such.

EI has roughly six components:

Self-awareness of emotion

The ability to handle emotion appropriately

The ability to motivate oneself by harnessing emotion

Awareness of emotional responses in others

The ability to relate to and manage emotional relations with others

Knowledge and practice of appropriate, situationally and culturally appropriate social skills like negotiation, making eye contact, etc.

These six components recur at different levels of complexity throughout an individual's life, and, therefore, emotional development is lifelong and somewhat cyclical.

Bar-On (2006) argues that EI is a non-cognitive intelligence and accordingly suggested emotional-social intelligence (ESI). His model is based on the philosophy that ESI is a "crosssection of interrelated emotional and social competencies, skills, and facilitators that indicates the way we understand and express ourselves, understand others and relate with them" (p.57), and 
encounter and deal with daily life. The ESI model includes 5main scales and 15 subscales. Table 3 summarizes concisely the ESI model's scales and subscales.

Table 3

The Scales and Subscales of ESI Model (Adapted from Bar-On, 2006)

\begin{tabular}{|c|c|}
\hline ESI & The ESI Competencies and Skills Assessed by Each Scale \\
\hline \multicolumn{2}{|c|}{ Intrapersonal (Self-awareness and self-expression): } \\
\hline Self-Regard & To accurately perceive, understand and accept oneself. \\
\hline Emotional Self-Awareness & To be aware of and understand one's emotions. \\
\hline Assertiveness & To effectively and constructively express one's emotions and oneself. \\
\hline Independence & To be self-reliant and free of emotional dependency on others. \\
\hline Self-Actualization & To strive to achieve personal goals and actualize one's potential. \\
\hline \multicolumn{2}{|c|}{ Interpersonal (Social awareness and interpersonal relationship): } \\
\hline Empathy & To be aware of and understand how others feel. \\
\hline Social Responsibility & To identify with one's social group and cooperate with others. \\
\hline Interpersonal Relationship & To establish mutually satisfying relationships and relate well with others. \\
\hline \multicolumn{2}{|c|}{ Stress Management (Emotional management and regulation): } \\
\hline Stress Tolerance & To effectively and constructively manage emotions. \\
\hline Impulse Control & To effectively and constructively control emotions. \\
\hline \multicolumn{2}{|c|}{ Adaptability (Change management): } \\
\hline Reality-Testing & To objectively validate one's feelings and thinking with external reality. \\
\hline Flexibility & To adapt and adjust one's feelings and thinking to new situations. \\
\hline Problem-Solving & To effectively solve problems of a personal and interpersonal nature. \\
\hline \multicolumn{2}{|c|}{ General Mood (Self-motivation): } \\
\hline Optimism & To be positive and look at the brighter side of life. \\
\hline Happiness & To feel content with oneself, others and life in general. \\
\hline
\end{tabular}

It is argued that EI increases with age (Humphrey et al., 2007); however, this claim needs to be assessed to provide empirical evidence. McPhail (2004) suggested a hierarchy of the progression and stages of EI illuminating the way EI develops with age (Figure 2).

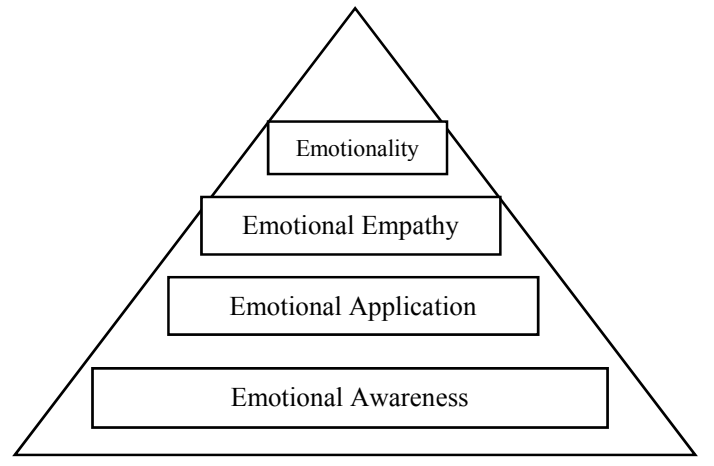

Figure 2.McPhail's (2004) hierarchy of emotional awareness

As Figure 2 clearly presents, the stages are emotional awareness, i.e., the awareness of one's feeling and emotions and being able to identify the emotions correctly; emotional application 
which is being able to recognize the appropriate emotions in specific conditions; emotional empathy involves the ability to enter into the feelings of others; and emotionality which is the "level of emotional self-awareness" and conscious use of emotions in making decisions (Humphrey et al., 2007).

\section{EI Measures}

There are considerable scholarly controversies regarding the nature of EI. On the one hand, it is claimed that EI is a cognitive ability and on the other hand EI is considered as a combination of affective, personality, and motivational traits and dispositions (Zeidner, Matthews, \& Roberts, 2012). These discussions paved the way for classifying EI measurements into two main categories: as a cognitive ability assessed through performance-based tests, and as a non-cognitive and personality trait measured via self-report inventories. In other words, to date, EI has been measured by rating scales, associated with typical performance, requiring persons to rate their agreement with items included in the questionnaire and "ability scales, associated with maximum performance", and "to process emotion-related stimuli and make a judgment"(AnguianoCarrasco et al., 2015). Three different ways have been put forward to measure EI; maximum performance measures based on the ability model of EI; rating scales based on the ability model of EI; and, rating scales of mixed models of EI (Anguiano-Carrasco et al., 2015). Although EI has traditionally been divided into two separate mutually exclusive categories, namely ability and perceived EI, Austin (2010) has argued that there is a unanimous consensus that the ability and the trait EI perspectives are distinct and do not measure the same construct, Salguero, Extremera, Cabello, and Fernandez-Berrocal (2015) recently argued that the two approaches are complementary.

One of the commonly used performance-based measures of EI is the Mayer-Salovey-Caruso Emotional Intelligence Test (MSCEIT) (Mayer, Salovey, \& Caruso, 2004a). Table 4 presents the layout of the MSCEIT adapted from Maul (2012).

Table 4

The Layout of the MSCEIT

\begin{tabular}{|c|c|c|}
\hline Branch Name & Task Name & Description of Task \\
\hline $\begin{array}{l}\text { Perceiving } \\
\text { emotions }\end{array}$ & $\begin{array}{l}\text { - Faces } \\
\text { - Pictures }\end{array}$ & $\begin{array}{l}\text { Identify the emotions expressed in pictures of faces } \\
\text { Identify the emotions expressed in pictures of artwork and landscapes }\end{array}$ \\
\hline $\begin{array}{l}\text { Using } \\
\text { emotions }\end{array}$ & $\begin{array}{l}\text { - Facilitation } \\
\text { - Sensations }\end{array}$ & $\begin{array}{l}\text { Rate the helpfulness of moods to activities } \\
\text { Generate an emotion on the basis of sensation words (cold, dark) and } \\
\text { compare the feeling to emotion words }\end{array}$ \\
\hline $\begin{array}{l}\text { Understanding } \\
\text { emotions }\end{array}$ & $\begin{array}{l}\text { - Changes } \\
\text { - Blends }\end{array}$ & $\begin{array}{l}\text { Identify emotions that result from intensifications of other emotions } \\
\text { Identify emotions that result from blends of other emotions }\end{array}$ \\
\hline $\begin{array}{l}\text { Managing } \\
\text { emotions }\end{array}$ & $\begin{array}{l}\text { - Emotional } \\
\text { management } \\
\text { - Emotional relations }\end{array}$ & $\begin{array}{l}\text { Rate the effectiveness of actions to situations involving one's own } \\
\text { emotions } \\
\text { Rate the effectiveness of actions to situations involving others' emotions }\end{array}$ \\
\hline
\end{tabular}

wWw.EUROKD.COM Doi: 
Although Brackett and Salovey (2006) argued that MSCEIT is a reliable and valid measurement of EI, further evidence is needed to provide firm support for the reliability and validity of MSCEIT. In addition to MSCEIT, the Emotional Quotient Inventory (EQ-I) and Selfreport EI test (SREIT), Emotional Competence Inventory (ECI), Bar-On Emotional Quotient Inventory (EQ-i), and Multifactor Emotional Intelligence Scale (MEIS) are other tests that can be used to measure EI (Brackett \& Mayer, 2003; Conte, 2005). However, there are key questions raised relating to the validity of these tests and also the validity of the EI construct.

\section{The continuing controversies and unresolved issues regarding EI}

There are a great number of issues and controversies surrounding EI that call for further research to clarify and shed more light on this issue. Mayer, Salovey, and Caruso (2004a, 2004b) in seminal papers aptly summarized the controversies and unresolved issues regarding EI that need to be discussed and investigated in detail. Table 5 represents the questions raised regarding EI.

Table 5

The Controversies Regarding EI The Controversies Regarding EI

How do we conceive of "emotion" of EI?

What is the point of attempting to establish EI as a standard intelligence?

Is EI a latent variable?

Are EI and emotional creativity the same?

Can EI be operationalized as an ability?

Do EI test items have a "right" answer?

Are tests of EI reliable?

Can EI be studied with methods beyond intelligence testing?

Do experts disagree over the answers to EI test items more than over the answers to cognitive intelligence test items?

Are EI test items different from cognitive test items in their behavioral relevance?

Do IE tests allow for nonconsensual, correct answers?

Are tests of EI valid?

Are written EI items ecologically valid?

Do tests of EI have content validity?

Do ability tests of EI possess incremental validity?

Is the variance predicted by EI trivial?

Do validity studies of EI depend too much on self-report criterion?

Do tests of EI have reasonable factorial validity?

Is the MSCEIT different from verbal and other intelligences?

Does the MSCEIT duplicate self-report measures of EI?

Does the MSCEIT simply duplicate already-existing measures of personality traits?

What is known about the predictive validity of EI? 
In brief, as the Table 5 indicates, there are many serious concerns regarding EI. The most important concern is the coherent definition and clarification of the EI construct. Moreover, the validity issue overshadows EI. Brackett, Mayer, and Warner (2004) stressed that the predictive validity of EI is not yet clear. In the same line of argument, Cherniss (2010a, 2010b) argued that lack of consensus regarding definitions and models of EI and the perceived problems regarding measuring EI are the on-going controversies surrounding EI. He put forward the emotional and social competence (ESC) concept. However, in response to Cherniss, Antonakis and Dietz (2010) cast doubt on the arguments, reasoning, and evidence presented by him. They claim that there is no need and, interestingly enough, no room for ESC, i.e., the emotional and social aspects of EI and we should only focus on ability definition of EI and its consequences. Roberts, Matthews, and Zeidner (2010) also posed three problems attributed to ESC measurements: ESC measures share empirical overlap with personality, it measures weak or unexpected correlations with emotions measures, and there is little problem of faking ESC measures.

In an invited review, Matthews, Zeidner, and Roberts listed seven controversial or problematic issues in research on EI. The issues are "lack of clarity of conceptualization, lack of a "gold standard" for measurement, overlap with existing constructs, lack of theoretical understanding, limitations in criterion-related validity evidence, uncertain practical relevance, and cultural influences on EI"(2012). This range of issues needs to be addressed and settled by experts and researchers within this field of inquiry. Matthews, Zeidner, and Roberts(year of publication) concluded that "The initial promise of research on EI has not been fulfilled, and it seems that the dream of establishing an "EQ" factor as important in human affairs as IQ will not be attained" (p.121).

\section{Concluding Remarks and Directions for Future research}

To date, EI has sparked a great deal of discussion. However, there are a great number of questions that remain unanswered. The claim that EI determines real-world success in education, occupation, and life needs to be validated. In fact, it can be argued that although many studies about EI have been conducted in management and organizational leadership fields, the discussions about applications of EI in education have remained at theory level. As regards to the functions and potential role of EI in education only a few studies have been conducted. One direction for further research is to investigate the mediating role of EI in enhancing education and academic success in different fields of study. Future research is encouraged to investigate the effect of EI on teachers' self-efficacy. Pishghadam and Sahebjam (2012) stressed that there is a paucity of research investigating the relationship between EI and teachers' effectiveness. In a similar vein, more research is needed to study whether facilitation and enhancement of EI leads to academic achievement in different age groups. In addition, one of the promising venues of research is to examine the teachability of EI and the consequences of teaching EI (Mayer \& Cobb, 2000). It is assumed that EI, in marked contrast to IQ, could be learned and improved consciously and strategically (Neophytou, 2013).

wWw.EUROKD.COM Doi: 
Matthews, Zeidner, and Roberts (2012) suggested four distinct types of constructs for research on EI that are worth considering. Table 6 represents these constructs and their possible current measures, key processes involved, adaptive significance, and trainability. These issues, as a road map, have the potential to spark a great deal of research resulting in convincing answers to the questions raised regarding EI.

Table 6

Four Distinct Types of Constructs for Research on EI (Adapted from Matthews, Zeidner, \& Roberts, 2012)

\begin{tabular}{|c|c|c|c|c|}
\hline Construct & $\begin{array}{c}\text { Possible current } \\
\text { Measures }\end{array}$ & Key Processes & $\begin{array}{c}\text { Adaptive } \\
\text { Significance }\end{array}$ & Trainability \\
\hline Temperament & $\begin{array}{l}\text { Standard personality } \\
\text { measures } \\
\text { Many trait EI scales }\end{array}$ & $\begin{array}{l}\text { Systems of integrated neural } \\
\text { and cognitive processes } \\
\text { controlling arousal, } \\
\text { attention, and reinforcement } \\
\text { sensitivity }\end{array}$ & $\begin{array}{l}\text { Mixed: most } \\
\text { temperamental factors } \\
\text { confer a mixture of } \\
\text { costs and benefits }\end{array}$ & $\begin{array}{l}\text { Low: Temperament is set by } \\
\text { genes and early learning }\end{array}$ \\
\hline $\begin{array}{l}\text { Information- } \\
\text { processing }\end{array}$ & $\begin{array}{l}\text { Speeded facial } \\
\text { emotion recognition } \\
\text { tasks } \\
\text { Tasks requiring } \\
\text { implicit processing of } \\
\text { emotional stimuli }\end{array}$ & $\begin{array}{l}\text { Specific processing modules } \\
\text { for processing emotional } \\
\text { stimuli }\end{array}$ & $\begin{array}{l}\text { Uncertain: Is speed of } \\
\text { processing necessarily } \\
\text { adaptive? }\end{array}$ & $\begin{array}{l}\text { Low: Except that fixed } \\
\text { stimulus-response associations } \\
\text { may become automatized } \\
\text { through training }\end{array}$ \\
\hline $\begin{array}{l}\text { Emotion } \\
\text { Regulation }\end{array}$ & Selected trait EI scales & $\begin{array}{l}\text { Self-concept and self- } \\
\text { regulation }\end{array}$ & $\begin{array}{l}\text { Predominantly but not } \\
\text { exclusively positive }\end{array}$ & $\begin{array}{l}\text { Moderate: Temperament has an } \\
\text { influence, but specific } \\
\text { strategies may be learnt, e.g., } \\
\text { via modeling and directed } \\
\text { practice }\end{array}$ \\
\hline $\begin{array}{l}\text { Context-bound } \\
\text { Emotional } \\
\text { Knowledge } \\
\text { and Skills }\end{array}$ & $\begin{array}{l}\text { MSCEIT } \\
\text { Situation judgment } \\
\text { tests }\end{array}$ & $\begin{array}{l}\text { Multiple acquired } \\
\text { procedural and declarative } \\
\text { skills }\end{array}$ & $\begin{array}{l}\text { Adaptive within } \\
\text { context for learning: } \\
\text { May be irrelevant or } \\
\text { counter-productive in } \\
\text { other contexts }\end{array}$ & $\begin{array}{l}\text { High: Learning of specific } \\
\text { skills and knowledge }\end{array}$ \\
\hline
\end{tabular}

It should be highlighted that the criticisms leveled against EI remain unresolved. EI theory needs to be validated. Van Rooy, Whitman, and Viswesvaran (2010), in line with Cherniss (2010a, 2010b), emphasize the urgent need for conceptual clarity for advancement of EI research and applications. As Waterhouse (2006) rightly underscores, "social psychology and social neuroscience research has outlined a more complex and varied array of human social-emotional skills than proposed in EI theory. The validity of EI remains to be determined" (p.218). She goes as far as to warn against teaching EI theory without considering its lack of empirical validity.

Moreover, another issue regarding the validity of EI theory is that EI has not been differentiated from personality and IQ; in addition, there are many conflicting constructs of EI because different researchers have proposed different definitions and constructs of EI.

It is also recommended to explore the relationship between emotional creativity and EI and the role of EI in enhancing creativity (Ivcevic, Brackett, \& Mayer, 2007). Likewise, further research is needed to shed more light on the relation of EI to actual behavior (Caruso, Mayer, \& Salovey, 2002).

We need to expand and enrich our understanding of the factors affecting and affected by EI. What is yet to be examined is validation of the EI measurements, in particular the MSCEIT. There 
is a paucity of research inquiring into the relationship of the branches of EI with one another. In addition, the nature of the tasks employed should be studied as well. As Harms and Crede (2010) emphasized, more research is needed to develop better assessment tools of EI. In the same manner, Cote (2010) argued that EI measures lack convergent validity; the purported EI measures might not correlate with each other simply because one or more of the EI measures lacks validity.

To verify the association between ability and perceived EI, further research is needed to investigate the integrative model; also, researchers might examine how and under which circumstances "actual EI performance and self-perceptions of EI interact to exert influence on psychological and social adjustment" (Salguero, Extremera, Cabello, \& Fernandez-Berrocal, 2015).

In conclusion, as Salovey and Grewal (2005) assert, despite the questions and discussions about the validity of EI measurement instruments, there is mounting evidence underscoring the potential of EI in predicting success in milestones of life, in particular, personal and work relationships. However, this issue is open to in-depth discussion and further research investigating various aspects of EI. As the pioneers of EI, i.e., Mayer, Salovey, and Caruso (2004b) mention, the idea of EI continues to raise a great deal of controversy. In sum, Mayer, Salovey, Caruso, and Sitarenios (2001) concluded that the development and understanding of an intelligent requires years of research. The EI research is in its infancy and researchers need to do more research to have a composite and complete picture of the theoretical framework of EI and more importantly the role and potential applications and functions of EI in a variety of fields, especially in education and language learning. In a nutshell, more interdisciplinary research on EI is needed.

\section{References}

Anguiano-Carrasco, C., MacCann, C., Geiger, M., Seybert, J. M., \& Roberts, D. (2015). Development of a forcedchoice measure of typical-performance emotional intelligence. Journal of Psychoeducational Assessment, 33(1), 83-97.

Antonakis, J., \& Dietz, J. (2010). Emotional intelligence: On definitions, neuroscience, and marshmallows. Industrial and Organizational Psychology, 3, 165-170.

Austin, E. J. (2010). Measurement of ability emotional intelligence: Results for two new tests. British Journal of Psychology, 101, 563-578.

Bar-On, R. (2006). The Bar-On model of emotional-social intelligence (ESI). Psicothema, 18(supl1), 13-25.

Brackett, M. A., \& Mayer, J. D. (2003). Convergent, discriminant, and incremental validity of competing measures of emotional intelligence. Personality and Social Psychology Bulletin, 29(9), 1147-1158.

Brackett, M. A., Mayer, J. D., \& Warner, R. M. (2004). Emotional intelligence and its relation to everyday behavior. Personality and Individual Differences, 36, 1387-1402.

Brackett, M. A., \& Salovey, P. (2006). Measuring emotional intelligence with the Mayer-Salovey-Caruso emotional intelligence test (MSCEIT). Psicothema, 18(supl), 34-41.

Brouzos, A., Misailidi, P., \& Hadjimatthoe, A. (2014). Associations between emotional intelligence, socio-emotional adjustment, and academic achievement in childhood: The influence of age. Canadian Journal of School Psychology, 29(2), 83-99.

wWw.EUROKD.COM Doi: 
Caruso, D. R., Mayer, J. D., \& Salovey, P. (2002). Relation of an ability measure of emotional intelligence to personality. Journal of Personality Assessment, 79(2), 306-320.

Cherniss, C. (2010a). Emotional intelligence: Toward clarification of a concept. Industrial and Organizational Psychology, 3, 110-126.

Cherniss, C. (2010b). Emotional intelligence: New insights and further clarifications. Industrial and Organizational Psychology, 3, 183-191.

Ciarrochi, J. V., Chan, A. Y. C., \& Caputi, P. (2000). A critical evaluation of the emotional intelligence construct. Personality and Individual Differences, 28, 539-561.

Conte, J. M. (2005). A review and critique of emotional intelligence measures. Journal of Organizational Behavior, 26, 433-440.

Costa, A., \& Faria, L. (2015). The impact of emotional intelligence on academic achievement: A longitudinal study in Portuguese secondary school. Learning and Individual Differences, 37, 38-47.

Costa, H., Ripoll, P., Sanchez, M., \& Carvalho, C. (2013). Emotional intelligence and self-efficacy: Effects on psychological well-being in college students. Spanish Journal of Psychology, 16(e50), 1-9.

Cote, S. (2010). Taking the "intelligence" in emotional intelligence seriously. Industrial and Organizational Psychology, 3, 127-130.

Ghanizadeh, A., \& Moafian, F. (2010). The role of EFL teachers' emotional intelligence in their success. ELT Journal, 64(4), 425-435.

Goldsworthy, R. (2002). Supporting the development of emotional intelligence through technology. Computers in the Schools: Interdisciplinary Journal of Practice, Theory, and Applied Research, 19(1/2), 119-148.

Goleman, D. (1995). Emotional intelligence: Why it can matter more than IQ. New York

City: Bantam Books.

Goleman, D. (1998). Working with emotional intelligence. New York City: Bantam Books.

Harms, P. D., \& Crede, M. (2010). Remaining issues in emotional intelligence research: Construct overlap, method artifacts, and lack of incremental validity. Industrial and Organizational Psychology, 3, 154-158.

Humphrey, N., Curran, A., Morris, E., Farrell, P., \& Woods, K. (2007). Emotional intelligence and education: A critical review. Educational Psychology: An International Journal of Experimental Educational Psychology, 27(2), 235-254.

Ivcevic, Z., Brackett, M. A., \& Mayer, J. D. (2007). Emotional intelligence and emotional creativity. Journal of Personality, 75(2), 199-235.

Lam, L. T., \& Kirby, S. L. (2002). Is emotional intelligence an advantage? An exploration of the impact of emotional and general intelligence on individual performance. The Journal of Social Psychology, 142(1), 133-143.

Matthews, G., Zeidner, M., \& Roberts, R. D. (2012). Emotional intelligence: A promise unfulfilled? Japanese Psychological Research, 54(2), 105-127.

Maul, A. (2012). The validity of the Mayer-Salovey-Caruso emotional intelligence test (MSCEIT) as a measure of emotional intelligence. Emotion Review, 4(4), 394-402.

Mayer, J. D., \& Cobb, C. D. (2000). Educational policy on emotional intelligence: Does it make sense? Educational Psychology Review, 12(2), 163-183. 
Mayer, J. D., \& Salovey, P. (1997). What is Emotional Intelligence? In P. Salovey \& D. J. Sluyter (Eds.), Emotional development and emotional intelligence: Educational implications (pp.3-34). New York: Basic Books.

Mayer, J. D., \& Salovey, P. (1995). Emotional intelligence and the construction and regulation of feelings. Applied \& Preventive Psychology, 4, 197-208.

Mayer, J. D., \& Salovey, P. (1993). The intelligence of emotional intelligence. Intelligence, 17, 433-442.

Mayer, J. D., Salovey, P., \& Caruso, D. R. (2004a). Emotional intelligence: Theory, findings, and implications. Psychological Inquiry, 15(3), 197-215.

Mayer, J. D., Salovey, P., \& Caruso, D. R. (2004b). A further consideration of the issues of emotional intelligence. Psychological Inquiry, 15(3), 249-255.

Mayer, J. D., Salovey, P., Caruso, D. R., \& Sitarenios, G. (2001). Emotional intelligence as a standard intelligence. Emotion, 1(3), 232-242.

McPhail, K. (2004). An emotional response to the state of accounting education: Developing accounting students' emotional intelligence. Critical Perspectives on Accounting, 15, 629-648.

Moafian, F., \& Ghanizadeh, A. (2009). The relationship between Iranian EFL teachers' emotional intelligence and their self-efficacy in language institutes. System, 37, 708-718.

Morrison, T. (2007). Emotional intelligence, emotion and social work: context, characteristics, complications and contribution. British Journal of Social Work, 37, 245-263.

Mortiboys, A. (2005). Teaching with emotional intelligence. New York: Routledge

Neophytou, L. (2013). Emotional intelligence and educational reform. Educational Review, 65(2), 140-154.

Pishghadam, R., \& Sahebjam, S. (2012). Personality and emotional intelligence in teacher burnout. The Spanish Journal of Psychology, 15(1), 227-236.

Rastegar, M., \& Memarpour, S. (2009). The relationship between emotional intelligence and self-efficacy among Iranian EFL teachers. System, 37, 700-707.

Rivers, S. E., Brackett, M. A., Reyes, M. R., Mayer, J. D., Caruso, D. R. \& Salovey, P. (2012). Measuring emotional intelligence in early adolescence with the MSCEIT-YV: Psychometric properties and relationship with academic performance and psychosocial functioning. Journal of Psychoeducational Assessment, 30(4), 344-366.

Roberts, R. D., Matthews, G., \& Zeidner, M. (2010). Emotional intelligence: Muddling through theory and measurement. Industrial and Organizational Psychology, 3, 140-144.

Salguero, J. M., Extremera, N., Cabello, R., \& Fernandez-Berrocal, P. (2015). If you have high emotional intelligence (EI), you must trust in your abilities: The interaction effect of ability EI and perceived EI on depression in women. Journal of Psych educational Assessment, 33(1), 46-56.

Salovey, P., \& Grewal, D. (2005). The science of emotional intelligence. Current Directions in Psychological Science, 14(6), 281-285.

Salovey, P., \&Mayer, J. D. (1990). Emotional intelligence. Imagination, cognition and Personality, 9(3), $185-211$.

Sharma, S., Gangopadhyay, M., Austin, E., \& Mandal, M. K. (2013). Development and validation of a situational judgment test of emotional intelligence. International Journal of Selection and Assessment, 21(1), 57-73.

Sherlock, P. (2002). Emotional intelligence in the international curriculum. Journal of Research in International Education, 1(2), 139-158. 
Van Rooy, D. L., Whitman, D. S., \& Viswesvaran, C. (2010). Emotional intelligence: Additional questions still unanswered. Industrial and Organizational Psychology, 3, 149-153.

Waterhouse, L. (2006). Multiple intelligences, the Mozart effect, and emotional intelligence: A Critical Review. Educational Psychologist, 41(4), 207-225.

Zeidner, M., Matthews, G., \& Roberts, R. D. (2012). The emotional intelligence, health, and well-being nexus: What have we learned and what have we missed? Applied Psychology: Health and Well-being, 4(1), 1-30. 